\title{
Hiring nurses re-entering the workforce after chemical dependence
}

\author{
Telva Miller ${ }^{* 1}$, Therese Kanai ${ }^{1}$, Mansureh Kebritchi ${ }^{1}$, Ruth Grendell ${ }^{2}$, Terry Howard ${ }^{1}$ \\ ${ }^{1}$ Center for Educational Instructional Technology, University of Phoenix, Phoenix, United States \\ ${ }^{2}$ University of Phoenix, Phoenix, United States
}

Received: May 4, 2015

DOI: $10.5430 /$ jnep.v5n11p65
Accepted: August 2, 2015

Online Published: August 17, 2015

\begin{abstract}
Although many studies may have been conducted to gain greater insight into the experiences of chemically impaired nurses, few, if any, studies focused on understanding and explaining the experiences of administrators who have hired, fired, or supervised chemically rehabilitated professionals. Imogene King's conceptual system and theory of goal attainment forms the framework for this study because the model is focused on three interacting systems identified as personal, interpersonal, and social systems. King views people as dynamic human beings whose discernment of persons, events, and objects guide their behaviors, social interactions, and physical well-being. This phenomenological study explored, the lived experiences of administrators, supervisors, and managers who have hired, fired, or supervised recovered chemical dependent nurses. Direct Nurse Managers' perceptions and attitudes about rehabilitated professionals from chemical dependency who are re-entering practice are explored as well. The participants in the study unveiled assumptions as well as personal and professional insights about chemically rehabilitated professionals returning to the work setting. The themes that emerged from the study included demonstration of compassion, concern for the assignment of duties, the influence of personal values (forgiveness, acceptance, and respect for others), and concern for eligibility of employment and for the successful completion of the IPN program. The results from the study add to existing nursing literature and may assist leaders to construct a work setting conducive to meeting the goals set forth by nursing administrators as well as provide insight into and acceptance of the rehabilitated professional in the work setting.
\end{abstract}

Key Words: Chemical dependence, Impaired nurse, Nurse rehabilitation, Nurse hiring

\section{INTRODUCTION}

Within the 21 st century, the U.S. healthcare system has continued to experience a nursing shortage that has critically affected the delivery of healthcare services. ${ }^{[1]}$ Problematic substance abuse by nursing professionals is an important and complex issue that may result in impaired practice that could endanger the health and safety of the public. ${ }^{[2]}$ Data have demonstrated that as many as one in five nurses in the United States are chemically dependent. ${ }^{[3]}$ In a study completed by Hardy (1987) ${ }^{[4]}$ approximately 40,000 to 75,000 chemically impaired nurses were actively working in the work force. Substance abuse creates a negative effect on the healthcare team as well as the nursing professional. ${ }^{[2]}$ According to a study completed by Ayyagari (2014), ${ }^{[5]}$ negative work relationships and insufficient administrative support underscore a dangerous work environment and burnout.

Nurses who struggle with drug misuse are described typically as over-achievers, possessors of advanced degrees, and graduates with high-ranking status. ${ }^{[6]}$ Nursing professionals who suffer from drug addictions consider themselves to be per-

*Correspondence: Telva Miller; Email: telvamiller@aol.com; Address: 2151 Consulate Drive, Suite 10, Orlando, Florida 32837, United States. 
fectionists, capable, responsible, efficient, and a manager's dream employee. ${ }^{[6]}$ The typical nurse can be described as skillful, intelligent, competent, caring, a motivator, giving of self, and hardworking. ${ }^{[7]}$ The drive to acquire acceptance or to rescue a nursing unit that is understaffed is recognized as an unconscious need for acceptance and approval. ${ }^{[6]}$ The loss of the skills of these impaired nurses to the workforce may be recovered by implementing prompt interventions.

Prevention, early identification, and treatment initiatives for nursing professionals suffering from substance abuse are crucial to ensure patients are receiving safe nursing care. ${ }^{[2]}$ It is important that measures be taken to assist the chemically dependent professional to transition with recovery, maintain nursing licensure, and provide safe, quality care. ${ }^{[8]}$

\subsection{Substance abuse among professionals}

Pooler, Sheheen, and Davidson (2009) ${ }^{[9]}$ stated that professionals are not impervious to chemical abuse because of their educations, disciplines, or levels of success in their fields. Healthcare professionals such as nurses, pharmacists, and doctors have a greater risk for developing chemical dependency because of access to medication within the workplace. ${ }^{[9]}$ The ANA has estimated that approximately $6 \%-8 \%$ of the nursing population has struggled with drug or alcohol dependence. ${ }^{[8,10]}$ Researchers have estimated that approximately $20 \%$ of nurses use some form of mood-altering medication. ${ }^{[1]}$ Thomas and Siela $(2011)^{[12]}$ postulated that 1 in 10 nurses are possibly impaired or in some form of recovery program for alcohol and drug addiction. Experts believe that these startling numbers are low estimates because substance abuse among nurses is not reported accurately due to continual negative stigmas associated with substance misuse. ${ }^{[11]}$

Substance abuse among healthcare professionals has been in existence for approximately 150 years and dates back to the Florence Nightingale era in the 19th century. ${ }^{[13]}$ The authors estimated addiction to be greater than $20 \%$ of the current nurse population. ${ }^{[13]}$ Studies have also revealed that substance abuse among nurses often began before or during nursing school. ${ }^{[14]}$ Fourteen percent of nursing students reported that alcohol abuse hindered school and work activity. ${ }^{[14]}$

\subsection{Effects of chemical misuse}

Substance addiction among healthcare professionals can be detrimental to the practitioner and the public. ${ }^{[15]}$ The workplace is devoid of comprehensive knowledge regarding drug addiction, which makes most nurses and administrators incapable of recognizing the manifestations necessary to diagnose drug misuse. ${ }^{[11]}$ Repeated drug misuse has deleterious effects on the body. ${ }^{[6]}$ Continuous substance abuse negatively impacts learning, motivation, self-control, and decision-making ability. Neurotransmitters in the brain are disrupted, resulting in diminished memory. ${ }^{[6]}$ Studies of substance abusers recurrently demonstrate data that display the prevalence of psychological instability, possible depression, and common feelings of inadequacy. ${ }^{[16]}$

Substance abuse "hijack[s] the motivation and pleasure pathways and systems of the brain". [17] Repeated exposure to the medication produces feelings of euphoria and a desire for more of the medication. Drug abuse can cause 2 to 10 times the amount of dopamine release. Effects of opiates on the brain are a decrease in the brains natural ability to produce dopamine (the neurotransmitter responsible for movement, emotion, motivation, and feelings of pleasure), decreased serotonin (the neurotransmitter that regulates memory processing, emotions, judgment, and planned actions), and other homeostatic mechanisms. ${ }^{[17-19]}$ Dopamine in excess levels produces a euphoric sensation which is what occurs with mind-altering medications. Research has supported that individuals who are addicted to mind altering substances have a decrease production of GABA (gamma-aminobutyric acid) a chemical that will assist with relieving anxiety and insomnia. ${ }^{[20]}$

The results of opiates on homeostatic mechanisms include symptoms of depression, anxiety, brain and body stress, and pain. ${ }^{[17]}$ The Center of Disease Control (CDC) reported that 29,000 unintentional deaths related to drug overdose occurred within the United States in 2009. ${ }^{[21]}$ Impaired Nurse (IPN) reported the deaths of three nurses in 2007, 11 in 2008, 17 in 2009, 5 in 2010, 12 in 2011, 13 in 2012, and as of February 2013, one death (L. Smith personal communication, January, 2013).

\subsection{Administrators' role}

It is important administrators and staff understand that substance and drug misuse is a disease and view colleagues as peers who require treatment. Implementing measures such as a return to work agreement and action plans for relapses will continue to assist with the rehabilitated professional's reentry into the workplace, and promote the recovery process. Administrators' understandings of chemical dependency may lead to the development and implementation of innovative programs that will enhance their ability to identify, assess, report, and address those issues that consistently lead to drug misuse. ${ }^{[2]}$ The results from the study may also inform administrators that strong educational programs, good monitoring systems, and firm enforcement of policies may reduce the level of substance abuse among nurses. ${ }^{[23]}$ Results of future studies might assist with supporting, refuting, and/or modifying implications of this study. 


\subsection{Background of problem}

The problem of substance abuse among nurses is not a new development. Awareness about drug abuse was gained during the early 1980s when the American Nurses Association (ANA) provided a definition of the impaired nurse. ${ }^{[24]}$ Statistical data revealed that the number of impaired nurses is estimated at 40,000-200,000 providers who have not been identified or received treatment for chemical addiction. ${ }^{\text {[25] }}$ During the 1980s, the ANA, the National Council State Board of Nursing (NCSBN), and specialty nurses associations began to address issues with respect to nurses practicing while under the influence of/or impaired by mind altering substances. ${ }^{[26]}$ During this same period, multiple studies revealed that Boards of Nursing in the United States of America (USA) received substance abuse reports or disciplined $67 \%$ of nurses for drug, alcohol, or psychiatric mishaps. ${ }^{[14]}$

Primitive efforts were concentrated on the acceptance of addiction as an illness "for which the nurse had a right to seek and receive treatment, access rehabilitation, and return to work when possible". [26] These efforts are important because chemical misuse and dependency cross many boundaries such as race, gender, culture, age, and class, making chemical dependency a widespread issue. ${ }^{[12,24]}$ Nurses involved in all areas of the nursing profession can be vulnerable to the phenomenon of chemical dependency.

Research findings have demonstrated that access to prescription medications such as hypnotics and painkillers play a prominent role in drug addiction. ${ }^{[26]}$ Prescription drug abuse is a serious problem among health professionals and duplicates the pattern of alcohol abuse by the public. ${ }^{[26,27]}$ Professional nursing organizations and regulatory agencies acknowledge that nursing professionals suffering from substance abuse jeopardize patient safety on every level. ${ }^{[28]}$ Nursing impairment is defined as the inability to complete a delegated task due to an impaired mental, or psychomotor function. ${ }^{[29]}$ Symptoms of chemical misuse include impaired judgments, slower reaction time, neglect of patient care, and prolonged complaints of patient physical discomfort because of drug diversion by the professionals for personal use. ${ }^{[30]}$ The performance of duties in any occupation in a debilitated state creates some liability or loss to society. ${ }^{[24]}$

\subsection{Causes of chemical dependence among nurses}

Stress has been credited as the leading cause of nurses developing chemical dependency. Extreme workloads; required shift changes, such as 7 a.m. to 7 p.m. and then alternating 7 p.m. to 7 a.m.; mandatory overtime; and floating to various units are examples of stressful situations in the nursing work environment. ${ }^{[15]}$

Published by Sciedu Press
The shortage of nurses within the profession has contributed to excessive workloads, which further increases stress levels and the risk of substance abuse. ${ }^{[15]}$ Nurses are challenged with demanding working assignments and conditions, understaffing, a high prevalence of patient deaths, an erratic work pace, and excessive work demands. Additional work stressors might include increased susceptibility to active infections harbored by patients through the handling of contaminated body fluids, accidental needle sticks, and exposure to dangerous medications such as those used for chemotherapy. ${ }^{[31]}$

\subsection{Addressing impairment}

During the 1980s, when nurses struggling with substance abuse were identified as chemically dependent, the disciplineonly approach was enforced. Administrators believed the only way to protect the public was to remove unsafe nurses from the work setting. ${ }^{[14]}$ Nursing regulatory agencies began to notice that the discipline-only approach did not address the chemical dependency, and as a result, new policies were considered and other approaches emerged. New policies have been generated by the American Nurses Association. ${ }^{[32]}$

\subsection{Reviewing and investigating allegations}

Under the Americans with Disabilities Act (ADA) of 1990, a person with special needs possesses a physical or mental impairment that "substantially limits a major life activity". [33] Aquila (2008) ${ }^{[33]}$ further indicated "a person who has a past record of such an impairment, or a person who is regarded by other people as having such impairment" would fall under the umbrella of a special needs status. An individual with special needs cannot be denied employment because of an inability to meet the physical or mental obligations deemed necessary to complete the job task effectively.

The state boards of nursing determines the rules and regulations with respect to the interpretation of what comprises misconduct, unprofessional conduct, incompetence, and unfit practice by a nursing professional. ${ }^{[34]}$ The investigation process includes an interview of witnesses, documents including medical records, policies and procedures, and the site of the alleged occurrence. ${ }^{[20]}$ Once a nursing professional is suspected of or concedes to substance abuse, the violation falls under the guidelines of unprofessional conduct. ${ }^{[34]}$ State regulations govern certain acts that might require disciplinary action against the professional. ${ }^{[35]}$ Violations would include: (a) drug diversion; (b) positive drug screen for a substance not prescribed; (c) violation of a state or federal narcotics or controlled substances law; (d) illegal use of controlled substances; (e) use of habit-forming medications, controlled substances, or alcohol impairment; and (f) failure to abide by 
the contract provisions of the nurse's assistance program. ${ }^{[34]}$

Once evidence regarding a substance abuse disorder or impairment has been presented, and the $\mathrm{BON}$ has concluded the professional has participated in unprofessional behavior and violated the Nurse Practice Act, the next step is for the BON to determine which sanctions are suitable for rehabilitating the nurse and whether a punitive or non-punitive approach is appropriate. ${ }^{[34]}$

\subsection{Returning to work}

Every State Board of Nursing has criteria for rehabilitated chemically dependent professionals returning to the work setting; however, individual institutions may require additional criteria for employment. Once the rehabilitated professional returns to work, the possibility exists for relapse with medication misuse. ${ }^{[36]}$ The administrator and human resources department may opt to create a written "return to work agreement." Any established agreement between the employee and the employer is independent of the Board of Registration in Nursing. ${ }^{[36]}$ The written contract may include limitations on the scope of practice, such as restricting the nursing professional from administering medications, implementing strategies for closer supervision, decreasing work hours, selecting particular shifts to work, and periodic random drug testing. ${ }^{[36]}$

\subsection{Problem statement}

Nursing administrators play a critical role in implementing changes that would decrease the nursing shortage. ${ }^{[37]}$ Administrators have expressed openly that nursing shortages place pressure on fellow colleagues, compromise patient care, and decrease the nurse to patient ratio. ${ }^{[8]}$ Fostering an environment that views substance abuse as a treatable condition sets precise expectations for the organization and provides the necessary support to assist the professional with successful recovery and transition into the work setting. ${ }^{[8]}$ Approaching professionals in a punitive manner causes delays with seeking assistance, frequent change of employment, and a postponement of the professional rehabilitated from chemical dependency returning to work. ${ }^{[8]}$ The specific problem is that despite a nursing shortage, hospital administrators are still reluctant to hire nurses who have been rehabilitated successfully from chemical dependency. ${ }^{[8]}$ Researching the problem may provide greater insight about the lived experiences of those who have hired or fired a recovered chemically dependent nurse and the reasons for reluctance to rehire.

\subsection{Theoretical framework}

Imogene King's (1981) ${ }^{[38]}$ conceptual system and theory of goal attainment forms the framework for this study because the model is focused on three interacting systems, identified as personal, interpersonal, and social systems. King's theory views people as dynamic human beings whose understanding of persons, events, and objects guide their behaviors, social interactions, and physical well-being. ${ }^{[39]}$ King posited that the personal system is the individual; the interpersonal system is the individual interacting and communicating with others; and the social system is society. The personal and interpersonal functions in the environment are identified as the social system. ${ }^{[38-40]}$

After a thorough examination of the theoretical framework, King's theory was used to better discern administrators' perceptions and acceptance of rehabilitated professionals, collaboration with colleagues, and principles for employing teamwork. ${ }^{[41]}$ The essence of the theory is that individuals are open systems that are continually interacting within their environments through personal, interpersonal, and social communication. ${ }^{[41]}$ The chemically dependent nurse (personal system) may interact with her nursing supervisor (interpersonal system) within the guidelines of the institution (social system) to seek help for rehabilitation. King's concepts is an appropriate model on which to formulate questions regarding the interactions of these three systems.

\section{Methodology}

The qualitative phenomenological design was selected because it provided greater insight of participants' perspective regarding the phenomenon under investigation. ${ }^{[42]}$ The qualitative method includes drawing inferences, employing semi-structured methods, and in-depth interviews to gain greater insight. ${ }^{[43] ~ " Q u a l i t a t i v e ~ m e t h o d s ~ e n t a i l ~ a s s u m p t i o n s ~}$ and approaches that are person-centered and focus on insiders' perspective". ${ }^{43]}$

Use of the qualitative research method provided a description of nurse managers' experiences with the rehabilitated, chemically dependent professionals. When using the qualitative research method, research questions usually begin with "what", "how", and "why" in order to probe the topic under investigation. ${ }^{[4]}$ In this study, the research questions began with "what" and "how." A lack of knowledge involving this phenomenon precipitated questions concerning the perspective of the nurse colleague or manager of a chemically impaired nurse. The responses to the questions provided immediate insight into the topic of how nurse managers experienced the phenomena.

\subsection{Research question}

The primary research question that guided this study was the following: Primary Question: What are the experiences and perceptions of administrators and managers working with nurses who are rehabilitated from chemical dependency? 
The interview questions were related to the administrators' experiences and perceptions of managing the processes and the policies for firing the impaired nurse and avoid any bias in hiring the rehabilitated impaired nurse back into workforce.

\subsection{Validity and reliability}

There are many views concerning the importance of validation in qualitative research. ${ }^{[45]}$ Triangulation was employed by accessing data from multiple sources, tape recorded interviews, and reflection. The aforementioned methods were also used to assist with suppressing prejudgments. This approach is customary in qualitative research. Transcripts were delivered to participants to review for accuracy. A follow-up phone call was made to participants with respect to changes after the review of the transcripts. Reliability was maintained by using a tape recorder and transcribing the interview. An editor was used to assist with editorial changes and analysis checking. Investigators who concentrate more on the description of the experiences of participants and less on interpretation promote credibility by completely exploring the human experience using the epoche method. ${ }^{[2,45]}$ Field notes, a tape recorder, and reflection were used to assist with suppressing prejudgments.

To control bias in this study, interview questions were carefully examined for items that might influence participants' responses to the questions. The epoche process also assisted to clarify bias. Epoch (also known as bracketing) allows investigators to "set aside their experiences, as much as possible, to take a fresh perspective toward the phenomenon under investigation". ${ }^{45]}$ Preconceived notions that rehabilitated chemically dependent nurses were unsuccessful with re-entry into the nursing profession were set aside. An openminded approach to the phenomenon was permitted by acknowledging that participants had valuable perceptions that might conflict with those preconceived notions.

\subsection{Sample and setting}

Participants in this study were recruited with the assistance of the vice president of human resources and the chief executive officer employed at a local hospital. The vice president of human resources emailed an invitation to all nursing administrators who had experience with hiring, firing, or supervising a chemically rehabilitated professional. Potential participants were selected according to whether they had experience with hiring, firing, or supervising rehabilitated nurses. The purposive sampling of these nursing administrators ensured participants could communicate and describe in detail the many specifics that gave the phenomenon its uniqueness. Within the first three weeks, 8 potential participants responded via telephone or email. This small sample included participants with various experiences and perspectives. Qualitative studies with phenomenological design may have a small sample size. Results will be applicable to similar context with similar populations. I contacted all 8 administrators to determine further if they met the criteria to participate in the study. Once qualified and willing participants were identified, arrangements were made via telephone or email to meet individually with each participant at a mutually convenient time and location. The final selection of participants was based upon the criteria outlined in the Invitation to Potential Participants letter.

\subsection{Data analysis approaches}

Colaizzi's method of phenomenological inquiry was used to conduct the study. Colaizzi's process consists of a description of the experiences, acquiring significant statements, formulation of meanings into themes, integration of themes into description, formulating the structure of the phenomena, and finally evaluating the result of the analysis. ${ }^{[46]}$ This method suited the study and permitted interviewing, writing detailed notes, listening to recorded interviews, and reading participants transcripts.

The reading of the transcripts unveiled that although each administrator had distinctive experiences with rehabilitated, chemically dependent nursing professionals, many of the administrators' perceptions were similar. Responses that were included related directly to the administrators' viewpoints of working with chemically dependent, rehabilitated nursing professionals and were extracted with a line-to-line analysis of the transcripts. Systematic meanings were assigned and clustered into categories. The results from the eight audiotaped, recorded interviews with nurse administrators were organized by research questions, comments, and pertinent quotations from the participants during the interview process. Significant statements were formulated into meanings and theme clusters extracted. Epoche was applied throughout the study as well as the data analysis process.

\section{RESUlts}

The primary research question that guided this study was the following:

What are the experiences and perceptions of administrators and managers working with nurses who are rehabilitated from chemical dependency?

The participants in the study unveiled assumptions as well as personal and professional insights about chemically rehabilitated professionals returning to the work setting. Upon completion of the interviews, the field notes and interviews were transcribed. Relevant to the study, key phrases that 
appeared throughout the interview process such as "I would give them another chance", "I have hired an IPN nurse", and there must be some support in place to assist the chemically rehabilitated professional return to the work setting, assisted in developing the themes for data reporting. The themes were organized based upon participants' responses to the interview questions. The phenomenon under investigation permitted participants to express their personal views about such professionals returning to the nursing profession.

The themes that emerged from the study included demonstration of compassion, concern for the assignment of duties, the influence of personal values (forgiveness, acceptance, and respect for others), and concern for eligibility of employment and for the successful completion of the IPN program. The data collected challenged the current literature that suggests that rehabilitated, chemically dependent nurses are not accepted back into the field. According to the data analysis and information collected from the IPN, rehabilitated, chemically dependent nurses are being welcomed back into the nursing profession.

\section{Clinical relevance}

The findings of the study revealed that greater insight regarding substance dependence is essential in the workplace. It is important that administrators and staff understand that substance and drug misuse is a disease and view colleagues as peers who require treatment. Implementing measures such as a return to work agreement and action plans for relapses will continue to assist with the rehabilitated professional's reentry into the workplace, and promote the recovery process. Administrators' understandings of chemical dependency may lead to the development and implementation of innovative programs that will enhance their ability to identify, assess, report, and address those issues that consistently lead to drug misuse. ${ }^{[22]}$ The results from the study may also inform administrators that strong educational programs, good monitoring systems, and firm enforcement of policies may reduce the level of substance abuse among nurses. ${ }^{[23]}$ Results of future studies might assist with supporting, refuting, and/or modifying implications of this study.

Living the Golden Rule is vital to the success of humankind, and demonstrating compassion requires a conscious effort to rise above selfishness and avoid causing distress to others. ${ }^{[11]}$ Fostering compassion in the workplace would create an impetus for minimizing judgment and safeguarding patients and peers from detriment. Understanding and embracing endeavors to choose and practice universal compassion in nursing will reduce antagonistic perceptions with respect to reporting impaired colleagues and further unveil interventions for the chemically dependent professional. ${ }^{[11]}$ Future research could be on a broader scale and include administrators' perceptions of the rehabilitated professional, implementation of hospital policies and procedures, inviting the impaired nurse constituents as well as the recovered professional for education about chemical dependency, and having a secure plan of action in place prior to incidences.

\section{Conclusion}

\section{Strategies for creating change}

Certain steps should be implemented by leaders in order to effect change in the nursing unit. ${ }^{[47]}$ The initial step is to define the primary outcome expected. It is essential that administrators possess the ability to identify the end step from the beginning of the change process. Administrators must demonstrate the ability to provide very lucid, articulated goals broken down into measurable objectives and outcomes associated with the anticipated change. ${ }^{[47]}$ Embracing the change process will assist administrators to identify how workers think, feel, and act. ${ }^{[47]}$ Administrators' insights about nursing units' daily functions permit supervisors the ability to identify and assess steps to a planned approach. ${ }^{[47]}$ Research about chemical dependency might provide strategic methods for education, reporting, and embracing the rehabilitated professional as well as a platform to assist with the next approach as progress continues. ${ }^{[4]}$

Greater insight about substance dependence is essential in the workplace. It is critical that administrators and staff perceive that substance and drug misuse is a disease requiring treatment. ${ }^{[11]}$ Although empathy has been cited as the trademark of the nursing profession, it is not demonstrated frequently toward an addicted professional. ${ }^{[11]}$ The ANA mandates "nurses in all roles" to assist the impaired professional and make certain they receive acceptable treatment and access to fair institutional and legal processes; however, the literature and personal assertions lead to a digression of this standard. ${ }^{[11]}$

\section{ACKnOWledgements}

This article was developed by the support of Center for Educational and Instructional Technology Research (CEITR), School of Advanced Studies, University of Phoenix.

\section{CONFlicts OF INTEREST Disclosure}

There is no potential conflict of interest to disclose. 


\section{REFERENCES}

[1] Denman B. Nursing shortages: A phenomenological study of nurses who worked in opioid treatment programs. (Doctoral dissertation). 2008. Available from: http://search.proquest.com/docvie w/304334879? accountid $=458$

[2] Nurses Association of New Brunswick. Recognition and management of problematic substance use in the nursing profession. 2011.

[3] Monroe TB, Pearson F, Kenaga H. Procedures for handling cases of substance abuse among nurses: A comparison of disciplinary and alternative programs. Journal of Addictions Nursing. 2008; 19(3): 156-161. http://dx.doi.org/10.1080/10884600802306024

[4] Hardy CJ. Behaviors of peers and supervisors as perceived by impaired nurse colleagues: A descriptive study. (Thesis). Available from: http://content.lib.utah.edu/utils/getfile /collection/etd1/id/85/filename/239.pdf

[5] Ayyagari A. Exploring the Dynamics of High-Challenge Encounters in Residential Substance Abuse Treatment Settings. 2014. (Doctoral Dissertations). Available from: http://repository. upenn.edu /edissertations_sp2/52

[6] Patrick D. Chemical dependency among nurses, nursing students. Journal of Illinois Nursing. 2010; 107(1): 7-10. Available from: http://search.proquest.com/docview/928760 394 ? accountid $=458$

[7] Rhodes M, Morris A, Lazenby R. Nursing at its Best: Competent and Caring. OJIN: The Online Journal of Issues in Nursing. 2011; 16(2).

[8] Godfrey G, Harmon T, Roberts A, et al. Substance abuse among nurses. 2010. Available from: http://www.thefreelibrary.c om/Substanceabuseamongnurses.-a0235280477

[9] Pooler D, Sheheen F, Davidson J. Professional impairment: A history and one state's response. Journal of Addictive Diseases. 2009; 28(2): 113-23. PMid:19340673

[10] Kincheloe DM, Litzenburg TA, Hancock D, et al. Impaired health care practitioners: Help the healer heal himself. ED Legal Letter. 2010; 21(9): 97-108. http://dx.doi.org/10.1080/105508809 02772415

[11] Bettinardi-Angres K, Bologeorges S. Addressing chemically dependent colleagues. JNR. 2011; 2(2): 10-17. Available from: http://www.reshealth.org/pdfs/subsites/addictio n/addressing_chemically_dependen_colleagues.pdf http://dx.doi.org/10.1016/S2155-8256(15) 30281-7

[12] Thomas CM, Siela D. The impaired nurse: Would you know what to do if you suspected substance abuse? American Nurse Today. 2011; 6(8): 1-6. Available from: http: //www . americannursetoday.c om/article. aspx?id=8114\&fid=8078

[13] Monroe T, Kenaga H. Support not punishment is the key to tackling substance abuse and addiction among nurses, study suggests. Science Daily. 2011; 20: 3-4.

[14] Smith L. Nursing impairment and intervention protecting patient care through recognition and referral. 2012.

[15] Epstein PM, Burns C, Conlon HA. Substance abuse among registered nurses. American Association of Occupational Health Nurses Journal. 2010; 58(12): 513-516. http://dx.doi .org/10.3928/0891016 2-20101116-03

[16] Bowler JL. Identifying the Underpinnings of Compulsive Behavior: A New Measure of Addiction Proneness. (Doctoral dissertation). 2006.

[17] Tanner J. Addictions: A brain disease. 2013.

[18] Berumen LC, Rodriguez A, Miledi R, et al. Serotonin receptors in hippocampus. The Scientific World Journal. 2012. PMid:22629209 http://dx.doi.org/10.1100/2012/823493

[19] Malliarakis K, Lucey K. Social determinates of health: Focus on substance use and abuse. Nursing Economics. 2007; 25(6): 368-370.
Available from: http://search.proquest.com.ezproxy. apollolibrary . com/docview/236974029?accountid=458 PMid: 18240840

[20] National Council State Board of Nursing. Substance use disorder in nursing: A resource manual and guidelines for alternative and disciplinary monitoring. 2011.

[21] National institute on drug abuse to announce results of 2012 monitoring the future survey. Lanham: Federal Information \& News Dispatch, Inc. 2012. Available from: http://search.proquest . com/docview/1239626638?accountid=35812

[22] Hughes CM. A narrative inquiry: Nurses' perception of pain in the elderly in a nursing home. (Doctoral dissertation). 2008. Available from: http://search.proquest.com.ezproxy.apollo library. com/docview/304314861 ?accountid=35812

[23] Malliarakis KD. Chief nursing officers' management of nurses with substance use disorder. (Doctoral dissertation). 2012. Available from: http://search.proquest.com/docview/106926 5471 ? accountid $=458$

[24] Esquibel KS. Registered nurses' perceptions of working with chemically impaired registered nurse colleagues. 2009. Available from: http://search.proquest.com.ezproxy.apollolibr ary.com/docview/305165644? accountid=35812

[25] Berens MJ. Substance abuse: What is working and what needs refinement in the perspective of nurses in recovery. Association of Nurse Anesthetists. 2002; 67(2): 133-140. Available from: http://www.oxbridgewriters.com/essays/psychol ogy/nurse-chemical-recovery.php

[26] Naegle M. Nurses and matters of substance. National Student Nurses Association Imprint. 2006; 58-63. PMid:17252839

[27] McHugh M, Papastrat K, Ashton KC. Assisting the drug addicted nurse: Information for the legal nurse consultant. Journal of Legal Consulting. 2011; 22(3): 11-14.

[28] Leppanen ML. Factors substance-misusing nurses perceive as influential in choosing to seek help. (Doctoral dissertation). 2010 Available from: http://search.proquest.com.ezproxy.apol lolibrary.com/docview/757405157?accountid=35812

[29] Beckstead JW. Modeling attitudinal antecedents off nurses' decisions to report impaired colleagues. Western Journal of Nursing Research 2002; 24(5): 537-551. http://dx.doi.org/10.1177/0193945 02400446405

[30] Gminder J. Addiction in nursing. The Journal of Practical Nursing 2011; 61(3): 9-11. Available from: http://napnes.org/drupa 1-7.4/sites/default/files/pdf/jpn/JPN-61-2.pdf

[31] Moustaka E, Constantinidis TC. Sources and effects of work-related stress in nursing. Health Science Journal. 2010; 4(4): 210-216. Available from: http://search.proquest.com/docview/7586 56815 ? accountid $=458$

[32] American Nurses Association. Addictions and psychological dysfunctions in 36 nursing: The profession's response to the problem. Kansas City, MO: ANA. 1984; 2: 41-47.

[33] Aquila FD. School law for K-12 educators. Thousand Oaks, CA: Sage; 2008. http: //dx.doi .org/10.4135/9781483329109

[34] Bettinardi-Angres K, Pickett J, Patrick D. Substance use disorders and accessing alternative-to-discipline programs. Journal of Nursing Regulation. 2012; 3(2): 16-21. Available from: http://www.reshealth.org/pdfs/subsites/addict ion/substance_use_abuse.pdf http://dx.doi.org/10.10 $16 / \mathrm{S} 2155-8256$ (15) 30214-3

[35] National Council State Board of Nursing. Substance use, abuse and addiction. ASBN Update. 2012; 16(3): 15-17. Available from: https ://www.ncsbn.org/SUDN_10.pdf 
[36] Massachusetts nurses association: American health security act of 2011. (2011, May 10). U.S. Newswire. 2011. Available from: http://search.proquest.com/docview/865560084? accountid=35812

[37] Watson J. Caring science and human caring theory: Transforming personal and professional practices of nursing health care. Journal of Health Human Services Administration. 2009; 31(4): 466-482. PMid:19385422

[38] King IM. A theory for nursing: Systems, concepts, process. New York, NY: Wiley; 1981.

[39] Williams LA. Imogene King's interacting systems theory: Application in emergency and rural nursing. Online Journal of Rural Nursing and Health Care. 2001; 2(1): 25-30. Available from: http: //www.thefreelibrary.com/ImogeneKing'sinteractings ystemstheory:applicationinemergency . . .-a0174057681

[40] Plummer M, Molzahn AE. Quality of life in contemporary nursing theory: A concept analysis. Nursing Science Quarterly. 2009; 22(2) 134-140. PMid:19342712 http://dx.doi.org/10.1177/08943 18409332807

[41] Stevens DA. The impact of empowerment, collaboration, and teamwork on patient safety culture in the perioperative setting. Available from ProQuest Dissertations and Theses database. 2009.
[42] Creswell JW. Qualitative inquiry and research design: Choosing among five approaches. Thousand Oaks, CA: Sage; 2007.

[43] Sharak V. The lived experience of patients after receiving care in the emergency department: A phenomenological study. (Order No. 3531329, University of Phoenix). ProQuest Dissertations and Theses. 2011. Available from: http://search.proquest.com/docvie w/1151411176? accountid $=35812$

[44] Leedy PD, Ormrod JE. Practical research: Planning and design (9th ed.). Upper Saddle River, NJ: Prentice Hall. 2010. PMid:20639162

[45] Creswell JW. Qualitative inquiry \& research design: Choosing among five approaches. (3rd ed.). Thousand Oaks, CA: Sage; 2013.

[46] Turunen H, Perala ML, Merilainen P. Modification of Colaizzi's phenomenological method; A study concerning quality care. Hoitotiede. 1994; 6(1): 8-15. Available from: http://www.ncbi.nlm.nih.g ov/pubmed/8054217 PMid:8054217

[47] Cropley A, Dark M. Three stages to measuring change communication. Strategic Communication Management. 2009; 13(3): 10. Available from: http://search.proquest. com. ezproxy . apol lolibrary $\cdot$ com $/$ docview $/ 203581090$ ?accountid $=35812$

[48] Burke J. Facing up to drug diversion. American Journal of Health System Pharmacy. 1999; 56(18): 1823-27. PMid:10511230 